surprise, says Frédéric Kaplan, a computer scientist at the Swiss Federal Institute of Technology in Lausanne and co-principal investigator on the project, which has already worked on historical records in Venice, Italy. "As a project in cultural heritage, we were an outsider it is a great victory to get this far," says Kaplan.

The commission launched the original flagships in 2013 under its FET programme, which is part of the European Union's main Horizon 2020 research-funding scheme. The FET Flagships were designed to tackle major scientific and technological challenges and to contribute to societal and economic well-being in Europe. The commission stumps up half of the $€ 1$ billion for each and expects the project consortia to raise the rest.

The Human Brain Project and the Graphene Flagship launched first, after a call for proposals, and the commission added the Quantum Technologies project in 2017. Another flagship, on battery technologies, is under discussion.

Although based on the same principle as these initiatives, the structure and funding of future projects is likely to change - but it's not yet clear how. Similar large-scale research initiatives are likely to be included in Horizon 2020's successor, Horizon Europe, which will start in 2021 and end in 2027. The commission said that it could not yet provide detail on how "flagship-like" missions will work within Horizon Europe, because it is still in the early phases of design.

"The approach is quite different, and there isn't yet much clarity about how things will come together," says cell biologist Daniela Corda, director of the CNR Institute for Protein Biochemistry in Naples, Italy, and Italian delegate to the Horizon 2020 programme committee. .

\title{
Tropical Africa could be key to solving methane mystery
}

\section{Wetlands are a likely culprit for a spike in atmospheric concentrations of the greenhouse gas.}

\section{【}

BY JEFF TOLLEFSON K scientists have taken the most detailed measurements yet of the methane in the skies over tropical Africa. The data should help researchers to understand a mysterious spike in atmospheric concentrations of the powerful greenhouse gas, which began in 2007.

An aeroplane loaded with sampling equipment began flights in Uganda in January and ended last week in Zambia. Researchers sampled methane emissions emanating from papyrus swamps, burning farm fields and flatulent livestock. Early results confirm that Africa is playing a major, yet poorly documented, part in the global methane cycle, with enormous consequences for the global climate.

Between dodging thunderstorms, the team found massive methane plumes rising above wetlands in both Uganda and Zambia. Researchers targeted this particular habitat because previous studies ${ }^{1}$ suggested that wetland microbes might be responsible for the methane spike. Project scientists were also able to measure the methane contained in smoke plumes emanating from agricultural fires around Lake Victoria and in northern Uganda.

"We've already learned a lot," says Euan Nisbet, an Earth scientist at Royal Holloway, University of London in Egham, who leads a consortium of 17 research institutions involved in the campaigns. In 2016, with $£ 5$ million (US\$6.5 million) in core funding from the UK Natural Environment Research Council in Swindon, the consortium started fieldwork in Africa and elsewhere, in addition to computer modelling work, to try to understand what is

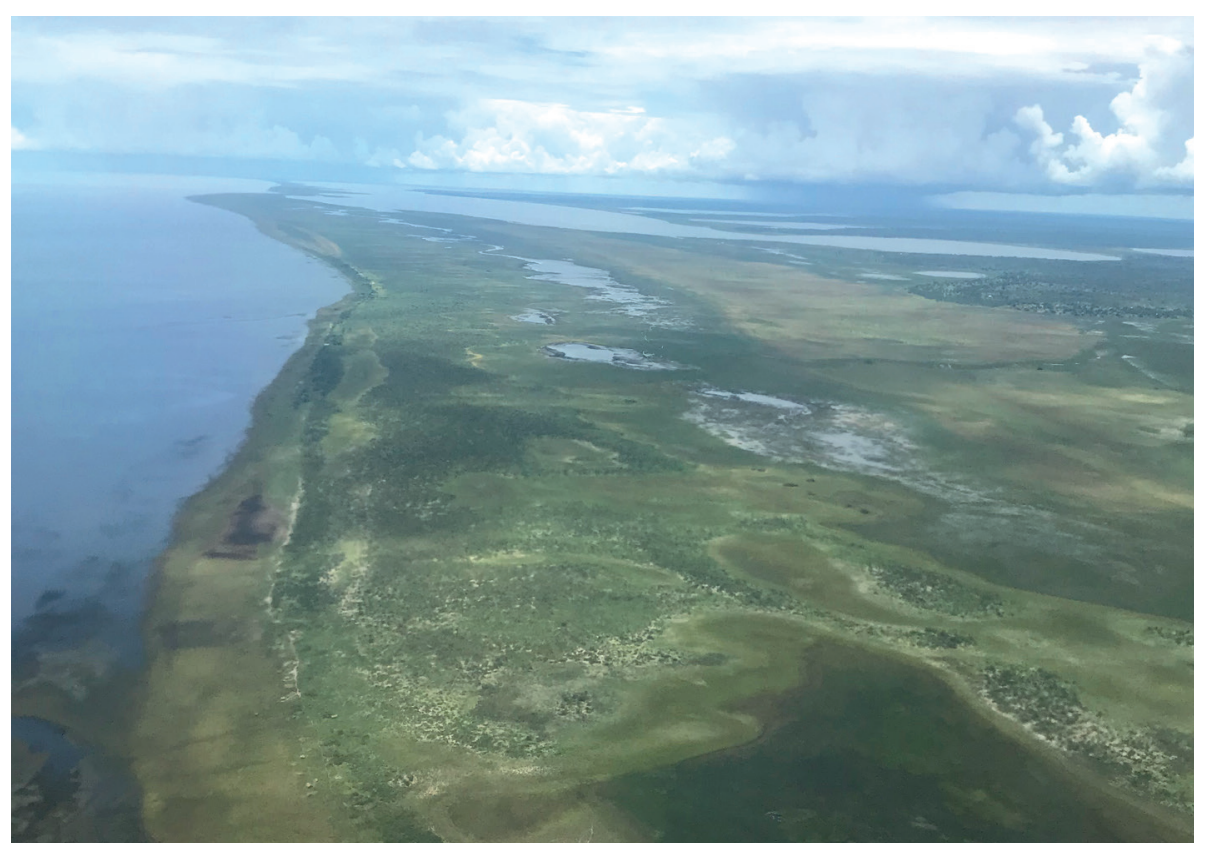

Microbes in Africa's tropical wetlands could be pumping large amounts of methane into the atmosphere.

driving the global methane increase. The project is scheduled to wrap up in 2020.

Instruments on the plane that the team flew over Uganda and Zambia collected data on the stew of gases and pollutants in the atmosphere. But the key to solving the methane mystery might be in the air samples that Nisbet's team gathered. The researchers returned to Britain last week with hundreds of flasks and plastic bags filled with the samples taken from the aircraft and by teams on the ground.

Nisbet and his colleagues will be looking at the isotopic signature of the methane emissions contained in their samples. Bacteria that consume carbon and produce methane in wetlands, for instance, tend to take up more of the isotope carbon-12. Fossil-fuel operations tend to release methane that contains more of the heavier carbon-13 isotope. Methane produced in a fire falls somewhere in between.

Scientists plug these chemical fingerprints into computer models to analyse the global methane trends documented at dozens of airsampling sites around the world. But data from the tropics, and from Africa in particular, is sparse, says Nisbet. 
- Globally, atmospheric methane concentrations have more than doubled since the pre-industrial era, to around 1,860 parts per billion (p.p.b.). Methane levels remained fairly constant from 1999 to 2006, averaging 1,774 p.p.b. - but then they started rising again. Many researchers initially thought fossil-fuel emissions could be responsible, but the evidence from subsequent isotope studies ${ }^{2}$ suggests that atmospheric methane is getting lighter, not heavier.

"A lot of the extra emissions seem to come from the tropical region, and that points to a larger contribution from wetlands," says Stefan Schwietzke, an atmospheric scientist who is now with the Environmental Defense Fund, an advocacy group based in New York City.

Other studies have suggested that the methane spike could be due to increased emissions from agriculture in southeast $\mathrm{Asia}^{3}$ or to a subtle shift in the rate at which methane breaks down in the atmosphere ${ }^{4,5}$. And work ${ }^{6}$ led by John Worden, an atmospheric physicist at the Jet Propulsion Laboratory in Pasadena, California, indicates that shifts in the amount of methane from sources including fires and fossil fuels could explain the increase, as well as changes in the isotopic signature of the greenhouse gas in the atmosphere.

But the uncertainties in all these analyses are large enough that any of the proposed theories could be at least partially correct, Worden says.

With the isotopic signatures that Nisbet and his team will pull from their air samples from this and related field expeditions, modellers should be able to produce more accurate estimates of global methane emissions, including in the tropics. This should help scientists in their efforts to understand what is happening globally and, ultimately, how climate change will affect the methane cycle in the future.

But Nisbet cautions that campaigns such as the Africa project provide snapshots in time, and partial ones at that. "We're just scratching at the surface with this trip," he says. "We're going to have to go back again." -

1. Schwietzke, S. et al. Nature 538, 88-91 (2016)

2. Nisbet, E. G. et al. Glob. Biogeochem. Cycles 30, 1356-1370 (2016).

3. Schaefer, H. et al. Science 352, 80-84 (2016).

4. Rigby, M. et al. Proc. Natl Acad. Sci. USA 114, 5373-5377 (2017).

5. Turner, A. J. et al. Proc. Natl Acad. Sci. USA 114 5367-5372 (2017).

6. Worden, J. R. et al. Nature Commun. 8, 2227 (2017),

\section{BY ALEXANDRA WITZE}

$\int \mathrm{s}$ ust a few years ago, Myanmar's geoscientists still relied on old-fashioned inked tracings to monitor earthquakes. Now they are using a real-time data feed from a high-tech network of seismic-monitoring stations dotted around the geologically active country. The transformation has propelled Myanmar to the forefront of seismic monitoring in southeast Asia - and is revealing its quake risk and speeding up its disaster response.

"It's gone from 0 to 100 in an amazingly short amount of time," says Eric Sandvol, a seismologist at the University of Missouri in Columbia.

Myanmar is perched on a small plate of Earth's crust beneath which the much larger Indian tectonic plate dives into the planet. That makes it geologically active, with six earthquakes of magnitude 7 or greater since 1930. Smaller quakes regularly rattle large parts of the nation.

With the new network, which collects data from 21 stations, scientists at the Department of Meteorology and Hydrology (DMH) in Nay Pyi Taw are issuing earthquake information and tsunami warnings faster and more accurately than ever before, says Yin Myo Min Htwe, a seismologist at the DMH. That means emergency responders can quickly understand where the greatest damage from a quake might be and react accordingly.

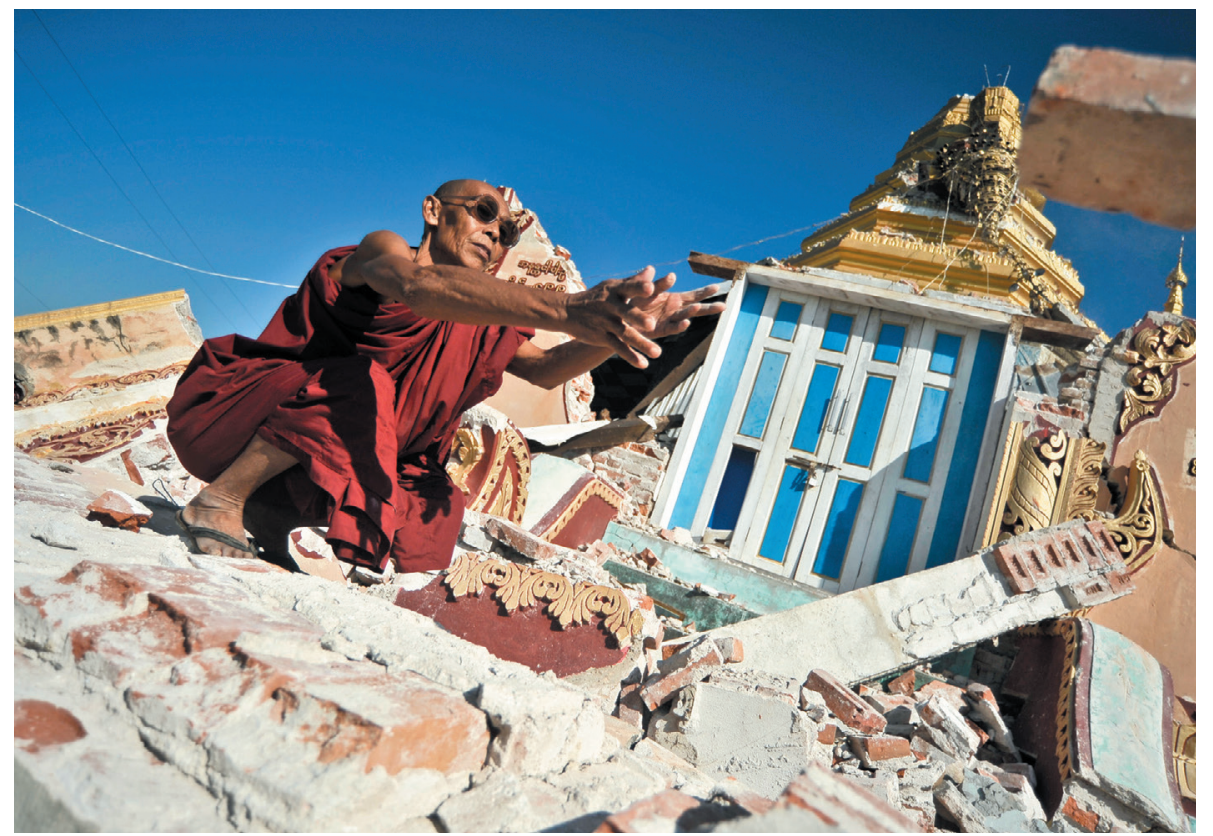

A monk clears debris from a ruined pagoda in Thabeikkyin, Myanmar, following an earthquake in 2012.

Even as Myanmar is bolstering its own monitoring, scientists from elsewhere are peppering the country with extra stations for research. Data from these will help them to understand the geology of the country, which sits between the Himalayas to the west and the Indonesian tsunami-generating zone to the east.

This month, a team from the German
Research Centre for Geosciences (GFZ) in Potsdam is temporarily installing 30 seismic stations in the north-west of the country, to analyse the structure of Earth's crust there. Research groups from China, India, Singapore and the United States have also descended on Myanmar, as the fledgling democracy begins to open up to the rest of the world. International scientists 